\section{UNDERGRADUATE REACTION KINETICS}

\section{Reaction Kinetics}

By Keith J. Laidler. Vol. 1: Homogeneous Gas Reactions. Pp. $\mathrm{x}+232$. 21s. net. Vol. 2: Reactions in Solution. Pp. $\mathrm{x}+136.17 s .6 d$. net. (The Commonwealth and International Library of Science, Technology and Liberal Studies. Chemistry Division, Volumes 1 and 2.) (London and New York: Pergamon Press, 1963.)

HESE two volumes together comprise a text-book on the kinetics of homogeneous reactions appropriate to honours chemists in their final or penultimate year of study. Chapter 1 of Volume 1 is concerned with the timedependence of the concentration of the product for various types of isothermal situation including reversible and consecutive reactions, and plug-flow systems, and its use in evaluating rate constants. Chapter 2 is an exposition of the collision and transition state theories, and Chapter 3 deals with the application of these, or modifications thereof, to homogeneous, gaseous, unimolecular and bimolecular, reactions of molecules, free radicals and atoms. The final chapter deals with the properties of selected multi-stage reactions with considerable emphasis on the decomposition of single organic molecules and very cursory mention of mechanisms of hydrocarbon oxidation and polymerization. Volume 2 contains only two chap. ters: "General Principles" and "Reaction Mechanisms". The approach is almost entirely on the basis of the transition state theory which is used to unify the diverse effects on the rate of reactions in solution of changes of ionic strength, dielectric constant, external pressure and molecular structure (the Hammett, Brønsted and Taft relations). General acid and enzyme catalysis are also discussed in this chapter. The second chapter is a series of brief essays on the kinetics and mechanisms of processes such as proton-transfer, electron-transfer, organic substitution, hydrolytic, enzyme catalysed, and ionic polymeriza tion reactions.

The books are the first to appear in the series to be published in the Chemistry Division of the Commonwealth and International Library of Science, Technology, Engineering and Liberal Studies. In each volume there is placed between the preface and the first chapter "A Note to the Student", which explains that the books have been written particularly for undergraduates who have studied the elementary principles of physies and chomistry, including some thermodynamics, and it is against this background that their utility must be assessed.

Let it be said at once that there are many good features, not least of which is the price. For just under two pounds sterling the purchaser acquires a set of lucid notes complete with useful bibliographies, selected references and numerical problems. The careful study of the $\mathbf{3 6 0}$ pages should give him a good understanding at undergraduate-level of some of the basic principles and concepts necessary for the interpretation of homogeneous reactions. If he is stimu. lated to go further and read some of the other books which are recommended in the bibliographies, then all will be well indeed. If he does not do so and relies entirely on these two volumes for his perspective in this branch of reaction kinetics, then his view of some aspects will be seriously distorted. Thus, while he will understand the relation between relaxation time, $\tau$, and $k_{1}, k_{-1}$ and the equilibrium concentration for the ionic dissociation of a monobasic acid he will not appreciate how $\tau$ is determined. He will not understand quantum mechanical tunnelling, though the term is mentioned (Volume 1, p. 78), and will gain the impression that, pace Bell, Johnston et al., it plays no part in proton, or hydrogen atom, transfer reactions. The reader may also be confused by the fact that in the discussion on p. $133 \mathrm{et} \mathrm{seq.} \mathrm{it} \mathrm{is} \mathrm{not} \mathrm{made} \mathrm{clear}$ that methylene can be formed in either a triplet ground state or an excited singlet state and that it is only the latter which efficiently undergoes both insertion' and double bond addition reaction to produce excited 'molecules' while the former produces either two radicals or a diradical adduct. Figs. 30 and 31 , Volume 1 , are so inaccurate in important details as to perpetuate dangerous mythology, and Fig. 16 of Volume 2 has the labels to the eurves interchanged. The treatment of polymerization reactions with the illogical allocation of polycondensation reactions to Volume 1, which is concerned with homogene. ous gas reactions, and the exemplification at the end of Volume 2 of ionic polymerization with an outmoded mechanism of cationic polymerization of isobutene and styrene, are, to say the least, unfortunate.

Most of the criticisms arise from the fact that Prof. Laidler, a distinguished figure in the field of reaction kinetics and a writer of great experience, perception and clarity, has attempted too much and ignored Francis Bacon's warning that "the lame in the path outstrip the swift who wander from it". If he had omitted complex gas and solution reactions and utilized some of the space thereby gained to fill the gaps in his treatment of elementary reactions what a splendid beginning to this series we should have had. As it is, the first three chapters of Volume 1 and most of Volume 2 indicate what might have been and alone would justify the purchase of these books by any chemistry honours undergraduate, to whom. despite these criticisms, I strongly recommend it.

F. S. DaInton

\section{SOLUBILITY TABLES}

\section{Solubilities of Inorganic and Organic Compounds} Edited by Prof. H. Stephen and Dr. T. Stephen. Vol. 1: Binary Systems, Part 1. Translated from the Russian. (London and New York: Pergamon Press, 1963.) 200s. net.

CCIENCE is largely concerned with the measurement of D physical and chemical properties and it is, therefore, not surprising to find that collections of quantitative data have always been among the most valuable and frequently consulted of all reference books. The collection and selection of such data are arduous but invaluable tasks and the appearance of a new work must always be welcomed by the scientific worker.

A reference work of this nature, which consists entirely of tabulated numerical data, can only be reviewed in a restricted fashion. When such a book is examined-it can scarcely be said to be read-it is only possible to make comparatively few checks on the correctness of data, and, unless the work contains many errors, these tests will in general be negative. The reviewer's main task, therefore, is to assess the scope of the work, the arrangement of data and the ease of retrieval of information.

Solubilities of Inorganic and Organic Compounds is the first English edition of an extensive Russian collection of data on the solubilities of elements and compounds in binary, ternary and multi-component systems. The data were compiled and selected from the international literature by a specially constituted panel appointed by the U.S.S.R. Academy of Sciences and it may be reasonably supposed that this is an authoritative work. The English edition is contained in two volumes: Volume 1 , bound in two separate parts, contains data on binary systems, and Volume 2, bound in three separate parts, covers other multi-component systems. Altogether there will be 6,540 tables contained in some 5,500 pages, which represents a very considerable collection of data.

This present published section of the work, Part 1 of Volume 1, which includes the whole of the material on aqueous binary systems, is organized into three main sections. There is a compact collection (Table 1) of concise data on the solubilities of some 2,000 inorganic, organic and organo-metallic compounds in water; a useful table for easy reference, which would have been of even 